\title{
Major concerns of FinTech (Financial Technology) services in the Korean market
}

\author{
KwangJong Ahn \\ June-Suh Cho \\ Hankuk University of Foreign Studies \\ Seoul, Korea
}

Keywords

FinTech, Data protection, Cyber-attack, Security, Regulation

\begin{abstract}
Technological innovation is the driving force of FinTech's growth. FinTech (Financial Technology) provides easing payment processes, reducing fraud, saving user's money, promoting financial planning, and moving a giant industry forward. FinTech is receiving a lot of attention in the finance and IT markets in the world. However, main concerns of FinTech services are regulations and technical problems such as government regulation, the security of customer's money and investments, protection of customer's data, cyber-attacks, lack of expertise, and so on. Especially, the major issues of FinTech are security and stability which are essential as well as ease of use. No matter how they introduce new technologies and user convenience, FinTech got the trust of our customers. As a leader of FinTech, we discuss the major concerns of the FinTech security with Korean market case. Also, regulation has slowed the development of the FinTech industry. With the unreasonable regulation system in Korea, FinTech is in a lot of controversies between finance and industry. People in Korea have already had a significant amount of experience with FinTech. The most prevalent examples of FinTech in Korea are Internet $\mathcal{E}$ Mobile Banking and shopping with the mobile payment market.

In this paper, we discussed institutional and technical issues that should be considered for a successful settlement in Korea and suggested how to carry out an unprecedented financial regulation innovation for the activation of FinTech to activate and successfully establish FinTech.
\end{abstract}

Corresponding author: June-Suh Cho

Email addresses for the corresponding author: jscho@hufs.ac.kr

First submission received: $6^{\text {th }}$ August 2019

Revised submission received: $4^{\text {th }}$ September 2019

Accepted: $9^{\text {th }}$ September 2019

\section{Introduction}

The platform that uses FinTech around the world is growing more and more over the years. Today, people do not visit banks to deal with their financial affairs. Mobile FinTech service enables you to check banking businesses anytime without being limited by time and space. In the global financial market, FinTech is evolving the financial industry, creating a mobile revolution that transcends time and space.

FinTech is a combination of finance and technology. It covers financial services through the convergence of finance and IT, and changes in industries based on these services. FinTech's principle is to transform centralized financial services into P2P distributed services, which is a major distinction between electronic finance and FinTech. Recently, there are financial services such as mobile banking, app cards, personal property management, crowdfunding, robo-advisor, and so on. The industry changes include providing financial services such as payment and settlement systems, remittance directly to users using technology possessed by innovative nonfinancial corporations, such as Apple Pay and Samsung Pay. (Lee \& Kim, 2015; Ma \& Liu, 2017)

If traditional financial services are conducted facing customers directly at the bank, it is at the heart of FinTech that everyone can enjoy the same services without time and space limitations. "Now the bank is going to be invisible to the customer." Instead of disappearing physical space, virtual banking, which incorporates artificial intelligence, speech recognition technology or biological functions, is becoming a reality. The era in which the bank monopolizes monetary policy is gradually closing. 
In Korea, FinTech services such as Kakao Pay, TOSS, and Bank Salad are gaining great popularity due to the ability to access financial services more quickly and conveniently. Kakao Pay, which started its services in 2014, is a FinTech service that allows users to make payments by simply inputting the password when purchasing goods or transferring them to another account after registering their credit card information in the KakaoTalk application. Also, it provides a simple remittance service.

Users of the TOSS application can take advantage of the bank's automatic withdrawal service (CMS) feature without an authorized certificate, allowing them to send money in just 30 seconds. To compensate for the instability of the security system without an authorized certificate, TOSS maintains a high level of security with only three certifications: mobile phone occupancy certification, account occupancy certification, and identification system. In 2017, Rainist, a Korean company specializing in FinTech, launched a bank salad and provided an asset management service through an application that automatically records and analyzes the user's deposit, withdrawal, and transfer history. It is convenient because you can see all the transaction information of all financial companies just by linking the first official certificate.

As a smartphone has become popular in recent years, FinTech provides a variety of practical FinTech financial services such as big data, platform, cloud funding, simple settlement and remittance service, and the development is different day by day. Regulation has slowed the development of the FinTech industry, and security and privacy issues continue to be pointed out and focused on remittance and payment services.

In this paper, we discuss institutional and technical issues that should be considered for a successful settlement in Korea. Also, it presented the development direction of Fintech's prospects and issues in Korean market.

\section{Background}

FinTech (Financial Technology), meaning the convergence between finance and technology, is a buzzword for 2015. Mobile technology makes it easier for startups to run a business than at any time in history, driving a shift towards the FinTech era where IT makes use of finance. There is no exception to this megatrend, in the global financial investment industries. FinTech increases its presence in every corner of financial markets, even in those regarded as traditional businesses such as wealth management, brokerage, investment advising, the secondary market, clearing, and settlement, etc. Korea is a little bit behind this global trend but now is keeping pace in seeking for opportunities to push FinTech innovation forward.

The continuous growth of the investment has been powering the development of FinTech to advance on technologies breakthroughs in multiple areas, such as mobile networks, big data, trust management, mobile embedded systems, cloud computing, image processing, and data analytic techniques. (Abawajy, Wang, Yang, and Javadi, 2016; Gai, Qiu, Tao, and Zhu, 2016; Gai, Qiu, and Zhao, 2018; Lee \& Kim, 2015; Zhang, Yang, and Chen, 2016)

The fast development of technologies has led to the emergence of the new market, FinTech, which is very attractive for investors today. By now this market has a great number of different concepts: P2Pcrediting, E-wallets, Bitcoins, T-commerce, mobile banks, etc. Many of these tools have already heavily entered our ordinary life. People can obtain any credits through special services on the Internet from other users without the participation of banks, pay by credit card using mobile devices, and get information about expenses and incomes according to the card anywhere in the world. Users do not need to go to banks anymore and to spend their time on credit arrangements, currency exchange, to look for ATMs to remove cash. Purchases on the Internet can be paid not only in rubles but also in new digital currency. These tools make life easier, however, they pose a serious threat for banks. Now, bank institutions should create more convenient and utility services for the clients to keep clients. Therefore, bank and credit systems start to change actively. (PWC, 2017)

As a new trend, FinTech is a line of business based on using software to provide financial services. FinTech companies are generally startups founded to disrupt incumbent financial systems and corporations that rely less on software. FinTech companies provide easing payment processes, reducing fraud, saving user's money, promoting financial planning, and ultimately moving a giant industry forward. (Kauffman. \& Ma, 2015; Lee, Lee, \& Chang, 2016) We still many questions about the security 
issues in FinTech services. The main concern of FinTech products is the security of customer's money and investments, protection of customer's data, cyber-attacks, lack of expertise, and so on.

In Korea, FinTech is receiving a lot of attention in the finance and IT markets. As we know that FinTech is a combination of finance and technology. This means that financial services are delivered through IT solutions to allow the customer to receive more convenient financial services. People in Korea have already had a significant amount of experience with FinTech. The most prevalent examples of FinTech in Korea are Internet Banking and Internet shopping.

Other countries around the world are not actively using Internet banking and Internet shopping as much as Korea. It's not too much to say that this goes for the services offered as well. But Internet banking and online shopping do not make up the entire scope of FinTech. The FinTech solutions we have discussed up until now are technologies such as Alipay, PayPal, Samsung Pay and Apple Pay used by companies such as eBay and Amazon. (Lim, Kim, Hur, \& Park., 2019)

For FinTech companies, cybersecurity should be a top priority. Also, data security is another issue regulator are concerned about because of the threat of hacking as well as the need to protect sensitive consumer and corporate financial data. The online financial sector is also an increasing target of distributed denial of service_extortion attacks. This security challenge is also faced by historical bank companies since they do offer Internet-connected customer services. (Puschmann, 2017; Callen-Naviglia. \& James, 2018)

FinTech can be shown that social reactions due to the increasing demand of internet and mobile banking enabled and your smartphone.

Samsung and Apple have recently started the 'Samsung pay' and 'Apple pay' and banks are making efforts to seat the mobile payment market. In addition to traditional credit card companies such as Visa cards are ready to release the correspondence to the credit card you are using a fingerprint and pin-tech has accelerated the growth of the market.

But the important thing is always a prerequisite FinTech security and stability is essential as well as ease of use. No matter how the introduction of new technologies, because the meaning of existence unless FinTech got the trust of our customers is not.

Internet bank of the ICT infrastructure has the security issue of the non-face-to-face is done mostly online. As an example, in 2014 service that Apple pay in the United States was experiencing If you pay with stolen card numbers, which the credit when you add the card authorization process is relatively vulnerable. PayPal is also the day of the accident rate has been increased to $0.33 \%$. PayPal even a day.

Also, personal information leakage incidents, POS systems, such as hacking, large and small financial accidents are occurring constantly. FinTech is above all strengthening of the security. FinTech is desperate circumstances must be developed, preferably as a possible prerequisite to achieving the security services, and financial innovation.

New technology is exciting, but it can open many doors to new threats, such as the recent SWIFT attacks. For example, Bitcoins have already been under severe attack, and companies have already lost millions of dollars to cybercrime. These attacks have demonstrated the importance of security and controls from the start.

Also, new technologies make cybercrime investigations more difficult to solve due to anonymity and a lack of regulation at various levels. Hackers have a better understanding of the latest in FinTech than most chief information officers; FinTech is the biggest of technologies' many unknowns and has become a playground for hackers. Security forms the foundation of the financial services industry and, aside from convenience, keeping customer information secure is the biggest responsibility for any FinTech company. It takes a complex and systematic approach to address all the elements of cybersecurity and help a company be better equipped and educated to battle the full spectrum of potential attacks.

FinTech security needs to innovate. FinTech start-ups need to work closely with real hackers and catch up with the latest threats and vulnerabilities being exploited by the underground hacker community.

Are they familiar with the dark web and internet relay chats were hacker's login? Can they interact safely? Additionally, it will be difficult for them to have time for all these tests. This makes achieving absolute security for new technologies extremely difficult and the best way to handle this is to start thinking about security from the start. Bring security into the design and think of secure design patterns. 
Most developers see security as an impediment when they should see it to adapt speed and build trust with both users and regulators.

\section{Current Status of FinTech Industry}

As non-financial companies providing IT services provide financial services, FinTech is no longer the exclusive property of traditional financial institutions. This is because non-financial companies such as platform companies, ICT companies, and security companies are actively entering and expanding financial services. The industry classification of FinTech still has various definitions and classifications depending on the viewpoint of the stakeholders or the interpretation of its users. Further discussion is required because the concept of FinTech has not been defined clearly. However, in this thesis, I will distinguish broadly from online-based innovative financial services and ICT infrastructures and technologies based on them.

\section{Nearly US $\$ 100$ billion has flowed into fintech ventures since 2010.}

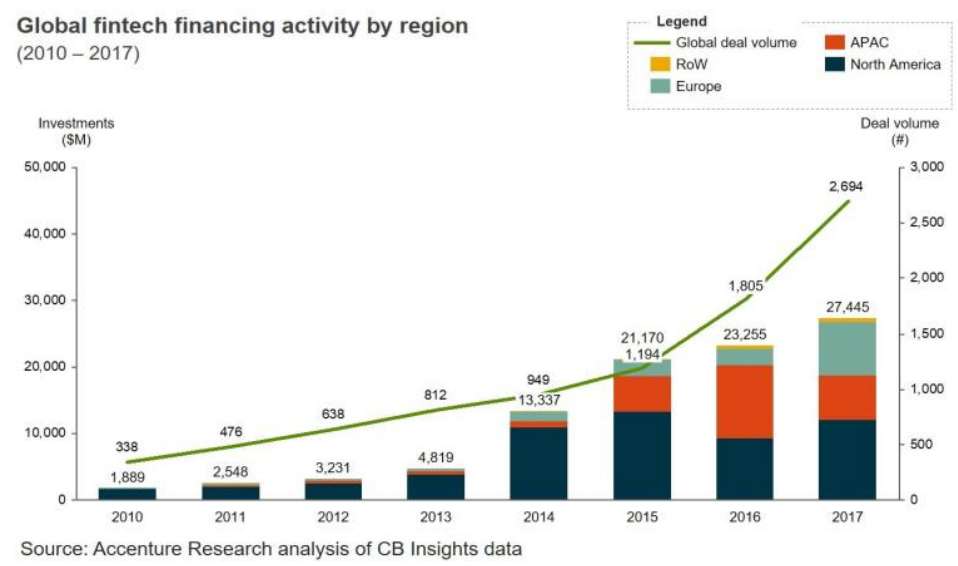

Figure 1. The World's FinTech Financing Deal Volume

Let's take a closer look at the current status of FinTech's financial industry and its domestic and overseas growth background. According to Figure 1, the world's FinTech financing deal volume already exceeds 1000 in 2015. In the two years from 2015 to 2017, FinTech's financing transactions have increased dramatically. The several factors $(\mathrm{KDB}, 2015)$ related to the development of FinTech is summarized with the change of consumption environment, the rapid speed of technological innovation and the competition of global IT companies.

The development of mobile and IT technologies and the explosive growth of smartphone users have changed the environment of consumption. Consumption is no longer limited by time and space. Mobile service users can purchase their goods or services anywhere, anytime, within 24 hours. As a result, the market for e-commerce and mobile consumption has grown rapidly around the world. In other words, thanks to the development of mobile IT technology, FinTech's growth was naturally expected.

Rapid technological innovation is also the driving force of FinTech's growth. The potential of the mobile market has become a reality due to the rapid development of technology. With the development of convergence technology, the range of services such as settlement, remittance, securities, asset management, and loans has expanded, and the benefits to consumers have also diversified.

Lastly, intensifying competition among global IT companies is one of the factors of the rapid growth of FinTech. With the proliferation of e-commerce and smartphones, IT companies have entered the financial market actively, and competition among global IT companies such as Apple and Google have intensified. In other words, the advancement into the mobile financial market took place all over the world, beginning with these global IT companies. In Figure 2 below, we can see the number of major trading companies in July 2017, which shows that the US and China are overwhelmingly dominated. Korea, on the other hand, has a size of \$ 51 billion, which is smaller than China, USA, and UK, but the domestic FinTech market is also growing. 


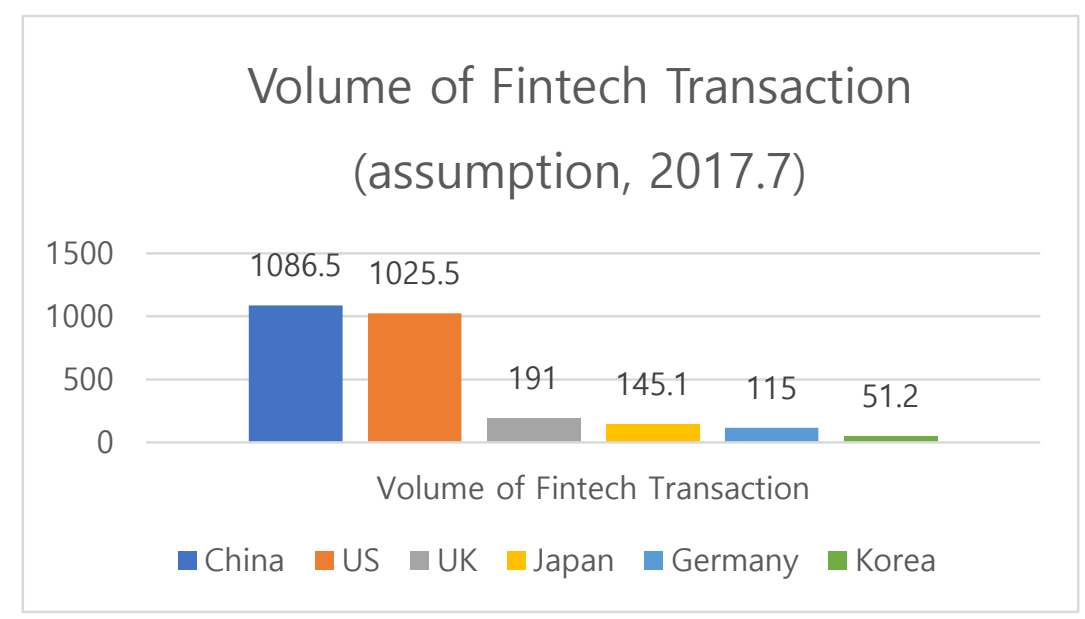

Figure 2. FinTech Statistics

Alibaba, an e-commerce company, provided artificial intelligence-based services for participating companies in China's biggest consumer festival, "Gwanggoon-je" on November 11, 2018, Alibaba's AI technology applied to logistics, cultivation of agricultural products, production of promotional videos, and translation services. Alibaba was expected to record sales of more than $\$ 32$ billion in sales, following sales of \$ 25.3 billion last year. Tencent, which provides Internet platform and game services, uses its distribution network to attract customers with Alibaba, and Pyeongan Insurance Company is responsible for developing insurance products. ZhongAn Insurance has become renowned as a world-class FinTech company through product development using Big Data, automated underwriting, and accurate risk management.

Oscar, a US online health insurance company established in New York in 2012, is a promising FinTech company that utilizes differentiated profit models and IT technology from existing insurance companies. Many existing insurance companies are trying to provide insurance services to healthy people who are relatively ill. Oscar, on the other hand, is an insurance company that broadens its customer base, prioritizes "customer health" and operates from the customer's perspective. For example, encouraging customers to continue to receive health screenings and keeping a certain amount of exercise will give customers up to \$ 20 in monetary incentives. Notable is Misfit Flash, Oscar's fitness tracker. Oscar's customers can check the number of steps, calorie consumption, travel distance, and sleep time through this wearable device. It also provides various healthcare services such as remote consultation with physicians through mobile applications. Oscar builds big data with data collected by mobile and IT technology. It pursues medical care, transparency in transaction and its cost.

\section{Dom estic Fintech"s Share of each}

\section{sector}
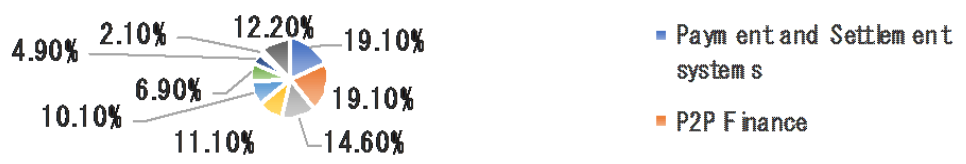

Figure 3 the annual size of domestic FinTech companies (The Bank of Korea, 2018)

Of course, the trading volume of the domestic FinTech industry is far below the US and China, but it is growing rapidly. As shown in Figure 3, the annual size of domestic FinTech companies is on the rise.

At the end of 2017, both the payment settlement category and P2P financing accounted for about $19 \%$, followed by the financial platform $(14.6 \%)$, security certification, and robot advisor followed by 
about $10 \%$. It is important to note that the investment in the FinTech company in the above figure 4 is diverse. In 2014, the investment was limited only in the area of blockchain and cryptographic assets. By the year 2017, however, it has emerged in various fields such as payment settlement, P2P financing, and crowdfunding.

\section{Issues of FinTech Financial Industry in Korea}

In the FinTech era, it is very unrealistic for many Internet platform operators to function as a platform for financial services, and financial regulators to pre-regulate numerous platform providers, so the security system will be improved based on principles. Also, since information security is not an option in online services, FinTech vendors are motivated to voluntarily develop security technologies. Therefore, it is more reasonable to strengthen the follow-up examination of how to deal with the user's personal information than the existing pre-regulation, and the government will increase the post-regulation opportunity through the evaluation of the IT condition. Finally, we will abolish the adoption of uniform technologies such as ActiveX and public certificates and ensure the security of technology to ensure the technology neutrality to enjoy better security.

In Korea, there are also issues related to government regulation in the FinTech industry. To increase the competitiveness of industries related to the fourth industrial revolution such as Korea's FinTech, it is suggested that the current regulatory threshold should be lowered. Korea has favorable conditions in the era of the fourth industrial revolution such as the world's best information and communication technology (ICT), but the unreasonable regulation system becomes a shackle. In the case of the FinTech industry, most of the Korean financial regulations based on a typical positive regulatory system are applied. Positive regulation is a prohibited and exceptionally permissive method in principle. FinTech is a new industry that combines ICT technology and financial business. It is a service that is significantly different from existing financial business. In particular, the regulation of $\mathrm{P} 2 \mathrm{P}$ finance and crowdfunding is pointed out as an unreasonable regulation system.

\section{Institutional Issues}

Financial institution experts and its service providers claimed that FinTech's growth in Korea is less prominent than in the US, China, and the UK. It is because those countries have already recognized the importance of FinTech and are actively working to foster the FinTech industry. The United States and Britain, the most developed countries in the financial sector, are investing and researching in FinTech services most actively, and Singapore, Israel, Germany, and Ireland are also making efforts to build FinTech infrastructure. Let's look at the case of the institutional infrastructure of the FinTech industry in the United States, Britain, and China who are leading the world's FinTech market.

The United States, the world's largest FinTech market, accounts for $83 \%$ of the world's FinTech investments. The United States is striving to maintain strict financial regulations to secure financial institutions and protect investors. Nevertheless, it adopts a 'negative regulatory system' that permits all but the prohibited ones.

This enables FinTech startup companies to create an environment that is easy to start any business with a new business model. In particular, the "No Action Letter" is a system that allows financial institutions to reply when a financial company asks for a review of the legality of a new product or starts a new business. If there is no problem as a result of the screening, it is a kind of "pre-emptive" that will not be brought into legal trouble or sanction later.

The UK, which is ranked second in the world after the US, is also rapidly growing into a FinTech powerhouse. As a result of the government's full support for FinTech, its infrastructure is seen as the main reason for its growth. Since the government created Tech City in 2011, transactions of the FinTech industry have more than tripled. UK introduced the world's first 'Regulatory Sandbox', which provides FinTech companies with the opportunity to test innovative financial products for a while without burdening regulators.

Unlike the general perception that the financial infrastructure is outdated, China's FinTech industry is growing very steeply. As of 2017, China's FinTech trade volume is expected to reach \$ 1.5 trillion by 2018, which is the world's top trade volume, about $\$ 100$ billion more than the US (about $\$ 1$ trillion). The Chinese government is trying to reduce the barriers to entry of new companies through 
deregulation of the FinTech industry and to promote financial innovation through competition with existing financial companies.

By not enforcing regulations in some companies or demonstration areas, companies have gained a competitive edge through diverse experiences. Problems found in the process of business operation are complemented by the legal and institutional environment so that they can be supplemented.

In the United States, the United Kingdom, and China, the FinTech industries discussed above are characterized by a sound financial infrastructure and relax government financial regulation. On the other hand, the growth of the domestic FinTech industry is still at a pace of growth compared to the world level. According to the announcement of 2017 and 2018 by venture capital $\mathrm{H} 2$ ventures and multinational consulting group KPMG, the Korean corporation among the world's top 100 FinTech companies was the only TOSS, which provides the remittance service.

As the financial regulation continues to be a stumbling block to the development of the FinTech industry, the government announced its commitment to support IT and financial convergence in 2015 and showed its commitment to fostering the FinTech industry. At the beginning of 2016, the Ministry of Science, ICT and Future Planning will relax regulations in the field of FinTech such as virtual currency foreign exchange remittance, P2P finance, and robo-advisor through the FinTech restructuring plan at the "New Industry Regulatory Innovation Ministerial Meeting". Despite the government's efforts to deregulate the financial system, experts point out that institutional management based on positive regulations, which lists only the pre-regulatory issues, is a problem.

Most of the regulations of the FinTech are negative regulations that allow only the prohibition and the rest of them freely, but most of them are positive regulations that can only allow businesses in the allowed areas. It is not easy for start-ups to carry out businesses without burdening regulations because it is a pre-regulation that is approved only after the business has been permitted and problems arise, rather than being regulated after the business.

As issues related to regulation in Korea, the separation of finance and industry has become a big issue. It is the law of logic that finance, and industry should be separated. Due to the separation of finance and industry and the regulations mentioned above, Korea 's FinTech is in a lot of controversies. Depending on how economic authorities relax regulations and create new regulations, Korea 's FinTech market will be decided.

\section{Technical Issues}

The concern about security threats to the new FinTech convergence services has risen recently. Hacking on Paypal in 2017(Fox Business, 2017) was a serious threat considering the increasing trend of 'Direct purchasing of foreign goods'. With more than 100 million users around the world, PayPal is a popular service for domestic users who purchase overseas goods directly because it is easy to pay by email address and password. However, the parent company, eBay, was attacked by hackers and the PayPal account linked to the eBay account was leaked out. Because FinTech's main means is smartphones, FinTech service providers are more concerned with smartphone security and users also need regular security checks and other controls. Park, Managing Director of HP Security Business, Korea said, "The old security threat has been a lot of attacks and DDoS(Distributed Denial-of-Service) attacks on the hardware itself, but recently, attacks on software such as apps are more dominant than the system itself. The concept of "secure coding (software development security)" is necessary from the time of development.

With the increasing number of companies that have personal information and financial information of consumers to provide FinTech service, problems regarding security issues are emerging. Various authentication means such as biometric authentication using fingerprint and iris as effective authentication means have been developed. Also, there is a need to build a Fraud Detection System (FDS) that can detect abnormal signs in advance and help identify the responsible areas in case of accidents.

Increase in the number of companies with personal information and financial information FinTech services in all fields such as settlement/remittance, Internet banking, crowdfunding, and financial data analysis should utilize personal and financial information of financial consumers. This means that the number of institutions that hold important information for financial consumers is increasing. 
First, if you look at the card payment in the field of payment/remittance, only the credit card company limited the storage and storage of personal credit card information. However, if the regulation is relaxed for easier settlement, it will be possible for FinTech companies that provide separate authentication means to directly hold credit card information of financial consumers. For this reason, a high level of information security management system required by credit card companies and banks is being demanded by FinTech companies.

Crowdfunding also requires the sophisticated information security management because the companies receiving the investors' money will have personal information and financial information of the donor and the investor. In the case of 'financial data analysis', it provides sensitive information such as consumption habits and life patterns as well as personal information and financial information in connection with big data analysis. For example, in the case of a service that finds an insurance product that is optimized for an individual, the consumer must provide not only personal information, but also sensitive information related to the insurance concerned.

Thus, for FinTech companies to provide customized and optimized services to financial consumers, they must have a large amount of information related to users. Increase in authentication methods in financial transactions, authentication plays an important role in ensuring reliability and security, such as identity verification, prevention of transaction denial, data integrity, and securing confidentiality. Offline financial transactions based on face-to-face authentication, such as existing handwritten signatures, have been converted to online transactions based on non-face-based authentication using a public certificate as part of the development of ICT technology. Recently, the security of the service has been improved by securely managing the various authentication means and various information.

The government intends to strengthen the follow-up inspection and clarify responsibility standards to solve possible security vulnerabilities following the pre-regulatory minimization policy. Fraud Detection System (FDS) is indispensable to enhance after-sales inspection. FDS helps prevent security incidents by identifying the abnormal signs before the settlement remittance transaction has proceeded and helps clarify responsibilities in the event of an accident. For this reason, FinTech and financial companies are rapidly establishing FDS, but small companies are having difficulty in building FDS due to the construction cost and large data processing.

\section{Examples of FinTech Companies in Korea}

The domestic FinTech industry is growing in the area of P2P finance and simple remittance and settlement.

Peer-to-peer finance is an abbreviation of "peer-to-peer finance", which means individualindividual financing. As such, P2P financing is a service that enables direct financial transactions between individuals based on the Internet without going through existing financial companies. In the past, financial transactions were made only through financial companies, but now it is possible to borrow money or invest surplus funds through the Internet.

Simplified remittance is a field of FinTech, which is rapidly growing around new electronic financiers, replacing remittance services of banks and other financial companies. As the security regulations, such as the abolition of the use of the authorized certificate in 2015, have been eased, the remittance service using the simple authentication method without the security card or OTP has been expanded. At present, Kakao Pay and TOSS have dominated the domestic remittance service market at $97 \%$.

Most of the users are in their 20s and 30s. The service is spreading around the 20s and 30s, who are less willing to use simple remittances and are looking for simplicity. According to the survey results, the male and female sex ratio was like $51.7 \%$ and $48.3 \%$, respectively. One of the biggest challenges for remittance companies is securing a profit model. Currently, Kakao Pay, Naver Pay, and Fink do not receive any remittance fees. TOSS and Check Pay, Payco, and Paynow are only charged on certain conditions. $72 \%$ to $100 \%$ of customers using the service of Kakao Pay and TOSS are 'free users'. TOSS and Kakao Pay recorded deficits by the end of last year. Instead of earning money from remittances, the company has chosen a profit strategy that secures customers and provides related financial services. As the number and amount of simple remittances increase, risk of financial soundness and data leakage is 
also expected to increase. Therefore, it is necessary to strengthen the security system of the simple remittance company.

\section{Concluding Remarks}

This paper presents suggestions along with concerns about Fintech's successful settlement and development in the Korean market. With the unreasonable regulation system in Korea, FinTech is in a lot of controversies between finance and industry. Also, the major issues of FinTech services are security and stability.

With the popularization of smart devices, the demand for financial services regardless of time and space will continue to increase. To effectively absorb these demands, FinTech must be supplied quickly, safely and conveniently. Therefore, more support and efforts are needed to create an environment for FinTech innovation.

\section{Implications}

FinTech, which is currently experiencing remarkable growth, will become an indispensable element in the financial market. Ultimately, the FinTech industry will increase the efficiency of financial transactions and enhance consumer benefits. Consumers will be able to reduce investment costs through the convenience of FinTech's financial services, and consumers' interests can be expanded by acquiring various financial information.

This is expected to be the foundation for the growth of young people and elderly people, who can be described as the financial weakness class. Still, the utilization rate of FinTech services for elderly people is only marginal to $4 \%$ as of 2018 . However, considering the size and growth rate of the FinTech industry in the future, it is reasonable to expect that the utilization rate of FinTech service of the elderly will steadily increase.

Also, spontaneous financial consumption will continue to expand as a variety of services and financial products tailored to consumers' financial needs arise. Like the case of Kakao Pay and TOSS, which we have discussed above, FinTech companies, which have introduced the simple remittance service as their main service, are currently offering a variety of financial services besides remittance. Bank Salad is also an innovative financial service that uses FinTech to make consumer asset management useful. The future of the FinTech industry is expected to become more diverse as the technological perfection or degree of innovation increases.

As a result of the growth of the FinTech industry, the public interest in financial investment has increased, and the FinTech financial market is expected to expand further. Individual financial information is no longer attributable to banks alone. Strategic alliances between financial institutions and FinTech companies and the bank's FinTech services have already created an efficient asset management market. In other words, consumers, financial institutions and FinTech companies in the financial market have a virtuous cycle structure and are moving toward profit for all. Also, international cooperation may play a key role in the development of more sophisticated cybersecurity innovations to protect FinTech.

\section{Prospects of FinTech Industry}

To nurture the FinTech ecosystem in the future, the financial investment industry, the government, and the FinTech company all desperately need efforts. First, the financial investment industry should take advantage of FinTech, which is traditionally out of financial services. In the direction of financial policy for FinTech, first, the transition of the regulatory paradigm is required. Minimizing preregulations on the FinTech industry and clarifying the burden of responsibility are essential for its development. It is also necessary to redesign the discipline of the electronic financial industry by implementing the principle of technology neutrality.

Also, it is important to restructure ineffective and old regulations in the existing financial sector by reorganizing the discipline centered on offline and to promote the introduction of Internet professional banks. At present, the domestic banks such as Shinhan Bank all dispute the fact that they are introducing FinTech themselves. The innovation of the sales channels of financial products and the promotion of crowdfunding, which is based on the online, are also evident.

The government should support the FinTech industry upbringing as an institutional device. Such institutional arrangements include the establishment of a FinTech support center or easing the barriers to 
electronic financial services. One of them is to increase the use limit of electronic payment means. At present, it is pointed out that FinTech is being ignored by FinTech companies or pre-founders because of its low professionalism.

The FinTech Support Center is a joint-venture TF established by the Financial Services Commission in March 2015 with the Korea Financial Supervisory Service, Koscom, Korea Deposit Insurance Corporation, and commercial banks as part of the FinTech industry promotion policy.

Countries such as the US, Europe, and China are already in full swing. Unlike the growth of the global FinTech industry, Korea is in the early stages of payment settlement, but it is now in its infancy in remittances, deposits, loans, investment advisory, and information protection. FinTech is a new blue ocean in the information protection industry. Moreover, efforts should be made to enhance competitiveness through cooperation with financial companies, along with the development of innovative technologies by security companies. FinTech will have a significant impact on the overall information security industry in Korea. For the FinTech industry to develop effectively and equitably, investment in information security companies should be expanded. Like the case in foreign countries, the driving force behind the development of the FinTech industry is the government's active investment and support measures. We should select the promising FinTech security companies and information protection startups and actively support them to invest in and partner with financial institutions.

Additionally, financial institutions and private large corporations should invest in promising security start-ups. Also, the environment should be created to promote deregulation and cooperation among related companies to enhance their competitiveness and self-sufficiency.

For the FinTech industry to be successful, various regulatory improvements need to be implemented. The essence of FinTech's success lies in security issues and deregulation in essentially every detail. However, focusing on the rapid growth of the global FinTech industry, the damage that can be caused when the security service is provided as the basic principle of the financial service, the damage will increase as the FinTech industry becomes more sophisticated. The convenience and security of financial services are inseparable and should not lose the balance of security and convenience.

Therefore, public consensus should be sought as technology and human beings harmonize with each other to be a proper combination of deregulation and security enhancement. In Korea, the financial infrastructure is world-wide enough to match the status of IT. It is not common in countries where money transfers are made in real-time by online banking. This relatively solid financial infrastructure can be a good base for the FinTech market to flourish. Online and mobile financial transactions are the most active in the world, and real-time financial transactions based on value-added networks (VAN) are possible.

However, FinTech has a unique financial environment that cannot be applied to the case of developed countries. In the era of convergence, connection, and collaboration, the information protection industry must develop along with financial innovation to succeed.

In the global era, this paper has a limitation that it is discussed mainly in the Korean market. This is because technical standards and institutions are different in each country, and technical problems and institutional problems should be solved together based on common standards in each country.

In the future, the Korean government plans to carry out an unprecedented financial regulation innovation for the activation of FinTech to activate and successfully establish FinTech. It will actively operate the financial regulation sandbox, the old regulatory reform, the investment of FinTech, Support, and strengthening digital financial security.

\section{Acknowledgement}

This study was supported by Hankuk University of Foreign Studies Research Fund of 2019

\section{References}

Abawajy, J., Wang, G., Yang, L., and Javadi, B. (2016). Trust, security and privacy in emerging distributed systems. Future Generation Computer Systems, 55(C):224-226.

Callen-Naviglia, J. \& James, J. (2018). Fintech, RegTech and the Importance of Cybersecurity. Issues in Information Systems, Volume 19, Issue 3.

Castiglione, Pizzolante, R., Santis, A., Carpentieri, B., and Palmieri, F. (2015). Cloud-based adaptive compression and secure management services for 3D healthcare data. Future Generation Computer Systems, 43:120-134. 
Gai, K., Qiu, M., Tao, L., and Zhu, Y. (2016). Intrusion detection techniques for mobile cloud computing in heterogeneous 5G. Security and Communication Networks, 9(16):3049-3058.

Gai, K., Qiu, M., and Zhao, H. (2018). Energy-aware task assignment for mobile cyber-enabled applications in heterogeneous cloud computing. Journal of Parallel and Distributed Computing, 111:126-135.

KDB Industrial Bank (2015). Domestic and Overseas Fintech Trends and Prospects.

Korea Institute for International Economic Policy (2016). UK Fintech Industry Support Policy and Implications.

Lee, T. and Kim, H. (2015). An exploratory study on FinTech industry in Korea: Crowdfunding case. In 2 nd Int'l conf. on Innovative Engineering Technologies, pages 58-64, Bangkok, Thailand.

Lee, Y., Lee, Y., \& Chang, B. A (2016). Study on the FinTech: The consideration of the Security, Journal of the Korea Society of Digital Industry and Information Management, Vol 12, No 3.

Lim, S., Kim, D., Hur, Y. \& Park, K. (2019). An Empirical Study of the Impacts of Perceived Security and Knowledge on Continuous Intention to Use Mobile Fintech Payment Services. International Journal of Human-Computer Interaction, Volume 35.

Ma, Y. \& Liu, D. (2017). Introduction to the special issue on Crowdfunding and FinTech, Financial Innovation, Vol 3, No 1.

Puschmann, T. (2017). Fintech, Business \& Information Systems Engineering, Vol 59, No 1.

PWC. (2017). Redrawing the lines: FinTech's growing influence in Financial Services, Global Fintech Report.

Telegraph Report (2017). Future of Fintech.

Zhang, Q., Yang, L., and Chen, Z. (2016). Privacy preserving deep computation model on cloud for big data feature learning. IEEE Transactions on Computers, 65(5):1351-1362. 